\title{
8 neuro-principios para el aprendizaje
}

Gabriela Pirela Sánchez

\section{Resumen}

$\mathrm{S}$ i el órgano en donde ocurre el aprendizaje es el cerebro, entonces deberíamos conocerlo mejor. ¿Los docentes saben lo suficiente del cerebro para enseñar?, si lo supieran ¿impactaría en sus clases? Estas preguntas pueden ser respondidas desde muchos ángulos, el que se abordará es el de las neurociencias por su relevante vinculación con el aprendizaje. Se pretende sensibilizar a los docentes de la necesidad de conocer los hallazgos de las neurociencias que impactan en la enseñanza y el aprendizaje. Se compartirán ocho principios sólidos que tienen la intención de dejar abierta la imaginación del lector, para que éste reinvente y dialogue creativamente con su didáctica. Se concluye proponiendo la práctica de algunos principios más respetuosos de cómo aprenden mejor los seres humanos.

Palabras clave: neurociencias, principios, aprendizaje, enseñanza, cerebro, neurotransmisores, emociones, procesos cognitivos, estrategias.

\section{Introducción}

La biología, las ingenierías, la medicina, el mundo de las comunicaciones y muchos campos más han evolucionado vertiginosamente; sin embargo, en la enseñanza el progreso es muy lento, seguimos viendo aulas repletas de la voz del profesor, siempre adelante y al centro, discursos reciclados con poca interacción, contenidos revisados rápidamente, materias vistas como islas, en lugar de continentes y el poder centrado en el docente, entre otros. Por consiguiente, tenemos en el aula apatía, aburrimiento, distracción, trabajos superficiales y más. Éste es un cuadro mucho más cercano a la educación durante la revolución industrial del siglo XIX que al presente siglo.

Por lo que, este artículo tiene la intención de despertar la necesidad de que los docentes conozcan el papel de las neurociencias, de responder a una mayor comprensión de nuestro cerebro y su relación con el aprendizaje a partir de ocho neuro-principios, mismos que podrán ser practicados, debido a su lenguaje claro y sugerente invitación a generar estrategias innovadoras que detonen un impacto positivo en el aprendizaje de los alumnos.
Pero ¿qué son las neurociencias? "Las neurociencias son el conjunto de ciencias y disciplinas científicas y académicas que estudian el sistema nervioso, centrando su atención en la actividad del cerebro y su relación e impacto en el comportamiento" (Gago y Elgier, 2018; citados en Araya y Espinoza, 2020).

\section{Ocho neuro-principios para el aprendizaje}

\section{La atención es un recurso muy limitado}

La atención realmente es un sistema complejo que encierra varias subformas de atención que se van adaptando según la tarea. En el aula, el profesor espera un tipo de atención "sostenida" que es limitada debido a que los procesos cognitivos funcionan integrándose, y se necesita elaborar la información, como afirmó Hernán Aldana en conferencia: "la mente debe pasearse adentro (aferente) y afuera (eferente) si me aburro, me quedo adentro, me distraigo; si me involucras y me muevo, me quedo afuera, atiendo" (Bertin, 2013). A continuación, se muestran datos del tiempo aproximado en promedio, de la atención "sostenida" por niveles educativos: 
Tabla 1. Promedio de atención sostenida por nivel educativo

\begin{tabular}{ll}
\hline Jardín de niños o preescolar & $5-8 \mathrm{~min}$ \\
\hline Primaria & $8-12 \mathrm{~min}$ \\
\hline Secundaria & $12-15 \mathrm{~min}$ \\
\hline Preparatoria & $15-18 \mathrm{~min}$ \\
\hline Universidad & 18 a $20 \mathrm{~min}$ \\
\hline
\end{tabular}

Elaborado por: Gabriela Pirela Sánchez a partir de la conferencia de Hernán Aldana, en YouTube por Javier Bertin, 2013.

Como se observa, este proceso es limitado, e invita a pensar en cómo dosificar el diseño de actividades que pretendan usar la atención por más tiempo.

\section{Es mejor modelar con todos los estilos de aprendizaje}

No existe evidencia científica que afirme que el estilo de enseñanza debe adaptarse a los estilos de aprendizaje (visual, auditivo y kinestésico) del grupo de alumnos. En un estudio (Krätzig y Arbuthnot, 2006, en Guillén, 2014), se hicieron pruebas para identificar este impacto y los resultados no fueron nada alentadores, pues no se pudo encontrar una mejoría en retener o recuperar aprendizajes dados, enseñados con el estilo de aprendizaje preferente.

Las pruebas científicas sí afirman que los estudiantes aprenden mejor usando los tres estilos preferentes, que hay una tendencia a ser más visual, pues somos un tipo de primate. En resumen, el estilo de aprendizaje en la clase dependerá sobre todo de la naturaleza del contenido. ¿No podemos imaginar a un alumno de preferencia auditiva pidiéndole a su profesor de álgebra que le enseñe sólo hablando verdad?

\section{Al cerebro le encanta la novedad}

La corteza cerebral es la última en desarrollarse en los humanos, en ella se llevan a cabo los procesos mentales más elevados como: solucionar problemas, el lenguaje, leer, planear, imaginar, la creatividad, la autoconciencia y muchos más. Se sabe que a esta estructura le gusta lo nuevo, pues la curiosidad nos ha permitido evolucionar. "Diversos experimentos han demostrado que el lóbulo frontal se activa más cuando la tarea es novedosa" (Guillén J., 2020), lo cual es una invitación muy puntual a variar recursos y estrategias de aprendizaje para ganar atención.

\section{Se aprende mejor con retos que con amenazas}

Al lóbulo pre-frontal le gustan los retos y desafíos, ello produce un neurotransmisor que emociona (la dopamina), y la emoción enciende la corteza y dirige la atención. Allí se generan el máximo de redes sinápticas que implican aprender y se consigue la tan anhelada motivación.

Cuando se percibe amenaza de cualquier tipo, el cerebro se estresa, siente desamparo o fatiga y se prepara instintivamente para la huida, es por ello que se debe promover un tipo de atención relajada, presión normal de cuando se aprende algo nuevo, pero que el reto sea apropiado y con acompañamiento; es decir ¡no está fácil, pero lo puedo lograr!

\section{Razón y emoción, pareja indisoluble}

Gracias a estudios neurobiológicos, hoy se sabe que todo aquello que produce complacencia o satisfacción se guarda con más fuerza en la memoria, es decir, se aprende. Cuando están involucradas las emociones se produce un neurotransmisor (la dopamina) que facilita que los viejos aprendizajes sirvan de andamiaje para los nuevos aprendizajes.

En gran medida, emoción y motivación dirigen el sistema de atención que decide qué información se archiva y se aprende. Lo que se aprende es influido y organizado por las emociones. Como maestros, es fundamental no olvidar que la razón y la emoción están platicando constantemente, por lo que se debe apostar por crear un clima emocional apropiado y de confianza.

\section{EI cerebro es un cerebro social}

El principio anterior está influido por este principio. Gracias a múltiples investigaciones se conoce que cuando se aprende en grupos pequeños o en pares, el aprendizaje se expande, esto sucede porque cuando los sujetos que aprenden hablan e intercambian distintos puntos de vista, hacen preguntas y las responden a su grupo, incrementa el desafío y la emoción e instantáneamente la mente construye ideas que no podría haber construido aprendiendo en solitario (Caine y Caine, R., 1997; citados en Silva, 2003).

La metodología del aprendizaje colaborativo, que es la base de otras metodologías activas, tiene toda la solidez y orientación para brindar herramientas en el aula presencial o virtual, que promuevan el aprendizaje en colaboración, ratificando que somos seres sociales y que estamos influidos por la naturaleza de interdependencia que debe ser promovida en el aula.

\section{7. "La búsqueda de significados es innata"}

(Caine y Caine, R., 1997; citados en Silva, 2003)

El cerebro se resiste a que le impongan cosas sin significado. La importancia de contextualizar los aprendizajes es fundamental; es decir, conectarlos en la medida de lo posible con la realidad de los estudiantes, si esto sucede se 
activan más lóbulos y esto favorece la capacidad de hacer relaciones, por lo que el conocimiento viaja más rápido a la memoria. El cerebro necesita referencias y los programas de estudio deberían mirar hacia la transversalidad. Integrando disciplinas se producen sólidos aprendizajes, pues a este órgano le encanta conectar lo nuevo con lo que ya tiene.

\section{La práctica cambia la estructura del cerebro}

Se podría afirmar que este principio no tiene nada de novedoso, pero las aulas siguen privilegiando conocimientos nuevos por día, sin práctica, sin transferencia y sin tiempo de reposo. La repetición y la práctica activa son los que producen verdaderos aprendizajes. Aquí se resalta la idea de que en el aula "menos es mejor que más", lo que significa respetar el tiempo para que se asienten los nuevos aprendizajes, se comprendan y se usen. Si no se usan, el cerebro tiene un sistema de economía maravilloso y los desechará en el olvido muy pronto.

\section{Conclusiones}

Se ha considerado prudente no sugerir estrategias de aprendizaje derivadas de cada neuro-principio, pues la invitación es que, al leer cada principio, éste sea un eje provocador para que el docente reinvente una pedagogía más alquimista, como haría un DJ mezclando con conocimiento y con emoción nuevas melodías.
Comprender e integrar los hallazgos de las neurociencias es empezar un proceso de transformación que debería seducir a los docentes. Integrar las disciplinas, es decir, hablar de la "transdisciplinariedad" de la enseñanza es no intentar aprender desde islas del conocimiento, sino desde una fusión que genere conexiones nuevas entre disciplinas completamente diferentes. Este escenario se vislumbra como la educación del futuro y del presente, sería sin duda uno de los retos que prometería aprendizajes de una manera más sólida, significativa y retadora, e implicaría también un nuevo tipo de docente.

La metodología del aprendizaje basado en proyectos cobra más relevancia que nunca en esta propuesta, pues traspasa cada uno de los neuro-principios expuestos, promueve un aprendizaje social, se resuelven retos desde un marco real de los alumnos; los proyectos invitan a un enfoque transdisciplinario del conocimiento, y van descubriendo nuevos significados impregnados de emoción.

Las neurociencias llegan al fin para construir un puente muy necesario entre las ciencias y la educación. Sin embargo, ellas no responderán todo por sí mismas, pues necesitan también de la observación o de la investigación-acción que los maestros descubran en el aula, consolidando el concepto de que el docente del siglo XXI deberá transitar en la didáctica como un acto de reinvención y apertura permanente. Las neurociencias tienen más de 25 años iluminando el camino de la enseñanza. Es momento de abrir esa ventana para dar lugar a un verdadero cambio de paradigma.

\section{Fuentes de consulta}

Araya-Pizarro, S. y Espinoza, L. (2020). (12 de agosto del 2020). Aportes desde las neurociencias para la comprensión de los procesos de aprendizaje en los contextos educativos. Propósitos y Representaciones, 8(1). Recuperado en: http://dx.doi.org/10.20511/pyr2020.v8n1.312

Bertin, J. (4 de enero del 2013). La neurociencia entra al aula III: Aprender y enseñar con todo el potencial del cerebro I. Conferencia del Dr. Hernán Aldana Decano de la Facultad de Ciencias Exactas y Naturales, de la Facultad de Ciencias de la Salud de la Universidad de Belgrano. YouTube https://www.youtube.com/watch?v=cud6MoCot4A

De la Barrera, M. y Donolo, D. (2003). Neurociencias y su importancia en contextos de aprendizaje. Revista Digital Universitaria. Recuperado el 4 de septiembre del 2020, en: http://bitly.ws/ajQK

Guillén, J. (16 de septiembre de 2020). Los cuatro pilares del bienestar: Transformando mentes para transformar la educación. Escuela con cerebro. Recuperado en: https:/escuelaconcerebro.wordpress.com/category/neurodidactica/.

Golberg, E. (2015). El cerebro ejecutivo. Barcelona, España: Editorial Planeta.

Silva, R. (2003). ¿La educación necesita realmente de la neurociencia? Estudios Pedagógicos, (29), 155-171. Recuperado el 20 de febrero de 2019, en: http://dx.doi.org/10.4067/S0718-07052003000100011

Tokuhama-Espinosa, T. (2011). What Mind, Brain, and Education (MBE) Science can do for teaching. New Horizons for Learning Quarterly Journal, Ix(1). Johns Hopkins University. 